\title{
KREASI KULUK KERINCI DARI ANYAMAN PANDAN
}

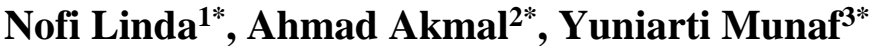 \\ Penciptaan Seni Kriya Program Pascasarjana \\ Institut Seni Indonesia Padangpanjang \\ Jl. Bahder Johan, Guguak Malintang, Padangpanjang, Kota Padangpanjang, Kode Pos 27126 \\ Sumatera Barat. Indonesia \\ Email:nofilinda86@gmail.com,ahmadakmal650@yahoo.co.id,yuniartimunaf1960@gmail.com
}

\begin{abstract}
Abstrak
Penciptaan karya seni kriya yang berjudul Kreasi Kuluk Kerinci dari Anyaman Pandan bertujuan untuk memperkenalkan kembali makna filosofis yang terkandung di dalam kuluk perempuan Kerinci. Metode penciptaan karya kriya kuluk ini meliputi metode observasi, wawancara, dan dokumentasi. Teori yang digunakan adalah teori bentuk, teori fungsi, teori warna, teori simbol dan teori kreasi. Penciptaan karya seni kriya ini menghasilkan kreasi kuluk yang terbuat dari pandan yang dianyam berduri dan dipadukan dengan bahan kain bludru. Untuk aksesorisnya didominasi warna emas yang menyimbolkan keistimewaan perempuan Kerinci di dalam rumah tangga. Kreasi kuluk Kerinci ini merupakan representasi perempuan Kerinci sebagai pemegang kunci, yaitu kunci umouh (rumah), kunci kamar, kunci bilik (lumbung padi), kunci pura (lemari), kunci peti, kunci dapur dan kunci hati.
\end{abstract}

Kata Kunci: kuluk, anyaman pandan, perempuan kerinci.

\begin{abstract}
The creation of a craft art entitled Kreasi Kuluk Kerinci dari Anyaman Pandan aims to reintroduce the philosophical meaning contained in the Kerinci female kuluk. The method of creating this kuluk craft work includes methods of observation, interviews, and documentation. The theories used are form theory, function theory, color theory, symbol theory and creation theory. The creation of this craft art resulted in the creation of a kuluk made of pandanus woven with thorns and combined with velvet fabric. The accessories are dominated by gold, which symbolizes the privileges of Kerinci women in the household. This Kerinci kuluk creation is a representation of Kerinci women as key holders, namely the umouh (house) key, room key, cubicle key (granary), temple key (cupboard), chest key, kitchen key and heart key.
\end{abstract}

Keywords: kuluk, pandan weaving, kerinci woman.

\section{PENDAHULUAN}

Kuluk merupakan ikat kepala atau penutup kepala yang digunakan oleh perempuan Kerinci sebagai mahkota kepala. Penciptaan karya seni kriya yang berjudul Kreasi Kuluk Kerinci dari Anyaman Pandan bertujuan untuk memperkenalkan kembali makna filosofis yang terkandung di dalam kuluk perempuan Kerinci yaitu dengan cara diletakkan di atas kepala sebagai mahkota kepala perempuan Kerinci, hal ini dimaknai bahwa perempuan Kerinci yang sudah menikah memiliki tanggung jawab yang harus dijunjung tinggi. Selain itu, tujuh kunci yang melambangkan bahwa peranan perempuan Kerinci setelah menikah adalah pemegang kunci di dalam rumah tangga, yaitu kunci umouh (rumah), kunci kamar, kunci bilik (lumbung padi), kunci pura (lemari), kunci peti, kunci dapur dan kunci hati.

Kata kuluk berasal dari kata tengkuluk, tetapi berbeda dengan tengkuluk yang dipakai dalam budaya Jambi secara umum. Kuluk Kerinci merupakan ikat kepala tradisional yang dipakai oleh perempuan Kerinci dilengkapi dengan busana tradisional Kerinci pada acara adat masyarakat Kerinci. Kuluk biasanya dipakai di atas kepala anak betino (perempuan) yang dilengkapi dengan busana adat seperti baju kurung, kain panjang (t'hap) dan selendang serta aksesoris pendukung seperti kalung, gelang, terompah dan jangki terawang yang berukuran kecil. Kuluk sebagai salah satu perlengkapan adat kaum perempuan Kerinci memiliki banyak makna yang terkandung didalamnya.

Di masa lampau, kuluk terbuat dari kain berwarna hitam yang diikat oleh lima puluh cincin dengan warna yang berbeda-beda seperti warna biru, merah, hijau, dan hitam. Cincin yang berjumlah lima puluh tersebut dimaknai dua puluh cincin melambangkan sifat Tuhan Yang Maha Esa, dua puluh cincin menyimbolkan undang-undang yang dua puluh, empat cincin bermakna sifat Nabi Muhammad SAW dan empat 
cincin melambangkan sifat mustahil Nabi Muhammad SAW serta dua cincin melambangkan pemaknaan siang dan malam. Cincin yang mengikat lingkaran kuluk disimbolkan sebagai ikatan suci laki-laki dan perempuan dalam pernikahan, saling memperoleh atau menjalankan hak dan kewajibannya, mentaati perintah Allah dan Rasulnya serta patuh pada hukum adat yang berlaku. Kuluk perempuan Kerinci ini tidak hanya digunakan ketika menjadi pengantin dalam prosesi pernikahan secara adat tetapi dalam acara adat masyarakat Kerinci secara umum. Sebagai penutup kepala pengantin wanita, kuluk disebut sebagai mahkota kepala perempuan Kerinci dan sebagai cerminan status sosial serta budaya dalam bentuk identitas diri dan simbol kehormatan perempuan Kerinci.

Berdasarkan penjelasan di atas bahwa sebagai Perempuan Kerinci, merasa tertarik dengan makna dan simbol yang terkandung di dalam kuluk tersebut. Dalam hal ini munculah keinginan untuk menciptakan sebuah karya yang terinspirasi dari makna serta nilai yang terkandung di dalam kuluk yang akan diwujudkan ke dalam karya seni kriya/kerajinan. "Seni kriya dapat didefinisikan sebagai kompetensi akademik karya visual dua dimensi dan/atau tiga dimensi yang mengedepankan kecerdasan konseptual yang berorientasi pada utility (kegunaan), significance (makna), dan aestethethic (keindahan), yang disampaikan berdasarkan dorongan hal tertentu melalui ekspresi (individu/ kolektif), serta kreativitas pengorganisasian unsur-unsur medium dan media rupa dengan teknik tertentu sehingga menghasilkan bentuk dan gayanya yang inovatif, indah dan unik".

Ketertarikan pengkarya untuk menciptakan karya seni kriya, terinspirasi dari nilai-nilai budaya serta makna yang terkandung di dalam kuluk masa lampau, yang akan diwujudkan melalui karya seni kriya kreasi kuluk Kerinci dengan bahan utamanya yaitu daun pandan berduri dan dikombinasikan dengan bahan pendukung seperti bahan kain beludru, manik-manik dan swarovsky. Proses penciptaan karya ini menggunakan teknik anyaman, teknik jahit dan teknik tempel.

Penciptaan karya seni kreasi kuluk Kerinci bertujuan untuk memperkenalkan kembali budaya Kerinci yang hampir dilupakan oleh para generasi muda di era modernisasi. Selain itu, dapat menambah minat para generasi muda untuk melestarikan budaya Kerinci dan menggali lebih dalam lagi tentang benda-benda budaya yang ada di masyarakat Kerinci. Secara akademik, proses ini dapat menjadi preferensi dan acuan dalam pembuatan karya seni inovasi baru bagi pengkarya selanjutnya. Selain itu, dapat menambah pemahaman masyarakat Kerinci khususnya perempuan Kerinci mengenai budaya, tradisi serta makna-makna filosofi yang terkandung pada kuluk perempuan Kerinci.

\section{KAJIAN TEORI}

\section{Teori Bentuk}

Bentuk dapat diartikan sebagai wujud, penampakan atau rupa dari suatu benda. Salah satu bentuk yang paling sederhana adalah titik, jika titik berdiri sendiri maka titik tidak mempunyai arti sebab titik tidak mempunyai ukuran, tetapi kumpulan beberapa titik akan membentuk sebuah garis, kemudian garis digabungkan dengan beberapa garis akan menjadi sebuah bidang dan jika dipadukan dengan beberapa bidang maka akan menjadi sebuah bentuk. Kartika (2017:27) berpandangan bahwa: "Bentuk (Form) pada dasarnya adalah totalitas dari karya seni. Bentuk merupakan organisasi atau satu kesatuan atau komposisi dari unsur-unsur pendukung karya, ada dua macam dari bentuk ini yaitu Visual Form merupakan bentuk fisik dari sebuah karya, dan Special Form yaitu bentuk yang tercipta karena adanya timbal balik antara nilai-nilai yang dipancarkan oleh fenomena bentuk fisiknya terhadap tanggapan kesadaran emosional”.

Berdasarkan paparan di atas, bentuk yang dihadirkan dalam proses penciptaan karya adalah kreasi bentuk kuluk dengan menggunakan teknik anyaman, yang dimodifikasikan kedalam bentuk baru dengan berpedoman pada bentuk kuluk sebelumnya.

\section{Teori Fungsi}

Fungsi atau kegunaan sebuah karya seni dapat dilihat dari bentuknya, misalnya bentuk dua dimensional berfungsi sebagai benda pajangan. Sedangkan bentuk tiga dimensional memiliki dua fungsi yaitu sebagai benda pakai dan sebagai benda pajangan. Kartika (2017: 46) menjelaskan bahwa: "keberadaan karya seni secara teoritis mempunyai tiga macam fungsi yaitu: fungsi personal, fungsi sosial, dan fungsi fisik. Fungsi personal sebagai instrumen ekspresi personal, seni semata-mata tidak dibatasi untuk dirinya sendiri. Maksudnya ia tidak secara eksklusif dikerjakan berdasarkan emosi pribadi, namun bertolak pada pandangan personal menuju persoalan-persoalan umum dimana seniman itu hidup yang nantinya akan diterjemahkan seniman lewat lambang simbol. Fungsi sosial merupakan kecenderungan atau usaha untuk mempengaruhi tingkah laku terhadap kelompok manusia. Ia diciptakan berdasarkan atas dasar penggunaannya pada situasi umum serta menggambarkan aspek kelompok sebagai wujud adanya perbedaan pengalaman personal. Fungsi fisik 
yang dimaksud berupa kreasi yang secara fisik dapat digunakan untuk kebutuhan praktis sehari-hari. Karya seni yang dibuat benar-benar merupakan kesenian yang berorientasi pada kebutuhan fisik selain keindahan barang itu sendiri”.

Berdasarkan uraian di atas, bahwa karya yang diciptakan juga memiliki tiga fungsi yaitu: a). Fungsi personal adalah suatu ungkapan perasaan dari diri pengkarya menyangkut karya yang diciptakan sesuai dengan sudut pandang pengkarya mengenai sesuatu yang berhubungan dengan kuluk Perempuan Kerinci. b). Fungsi sosial merupakan salah satu cara untuk menyampaikan sebuah pesan dan makna simbolis yang terkandung didalam karya kuluk yang diciptakan. c). Fungsi fisik yaitu sebagai mahkota perempuan Kerinci yang diletakkan di atas kepala.

\section{Teori Warna}

Peranan warna di dalam sebuah karya seni tidak dapat diabaikan begitu saja, sebab warna memiliki peranan yang sangat penting dalam menciptakan sebuah karya yang estetik. Menurut Kartika (2017: 46) bahwa: "Warna sebagai salah satu elemen atau medium seni rupa, merupakan unsur susun yang sangat penting, baik dibidang seni murni maupun seni terapan. Bahkan lebih jauh dari pada itu warna sangat berperan dalam segala aspek kehidupan manusia. Demikian eratnya hubungan warna dengan kehidupan manusia, maka warna mempunyai peranan yang sangat penting, yaitu: warna sebagai warna, warna sebagai representasi alam, warna sebagai lambang/simbol, dan warna sebagai simbol ekspresi". Warna merupakan unsur seni rupa yang muncul dari pigmen (zat pewarna) (Seragih, 2021: 304).

Pendapat lain seperti yang ditegaskan oleh Akmal (2013: 147) bahwa, warna adalah pigmen yang terdiri dari butiran halus yang mempunyai sifat pembeda antara yang satu dengan yang lainnya. Dari paparan yang dikemukakan di atas dapat disimpulkan bahwa warna memiliki peranan yang sangat pentng didalam sebuah karya seni agar tampilannya bervariasi dan tidak menimbulkan titik jenuh dari penikmatnya. Sehubungan dengan hal tersebut, dalam proses penggarapan karya kuluk yang diciptakan menggunakan warna khas masyarakat Kerinci antara lain merah, hitam, putih, kuning, dan hijau. Keseluruhan warna tersebut merupakan warna kontras yang menyiratkan pesan dan simbol. Masyarakat Kerinci lebih cenderung menyukai warna-warna panas, hal ini mencerminkan watak masyarakatnya yang memiliki karakteristik yang keras, giat, dan tanpa kenal menyerah dalam melakukan suatu pekerjaan.

\section{Teori Simbol}

Simbol merupakan sebuah penanda yang digunakan untuk memberitahukan sesuatu hal kepada seseorang. Simbol juga dapat diartikan sebagai tanda untuk memaknai sebuah benda. Hal ini di ungkapkan oleh Kridalaksana (dalam Sobur, 2003: 155) bahwa, biasanya terjadi berdasarkan metonimi (metonimy), yakni nama untuk benda lain yang berasosiasiatau yang menjadi atributnya.

Pernyataan di atas mengisyaratkan bahwa, dalam proses penciptaan sebuah karya seni, simbol merupakan sebuah tanda yang berfungsi sebagai alat komunikasi untuk menyampaikan pesan dan makna yang terkandung didalamnya. Melalui proses penciptaan ini pengkarya mengungkapkan atau pun menyampaikan tanda tersebut melalui bentuk yang dihadirkan sebagai contoh bentuk jangkoi (jangki) yang diaplikasikan sebagai salah satu unsur yang mendukung bentuk estetis dari kuluk. Tanda tersebut menyimbolkan bahwa masyarakat Kerinci mayoritasnya adalah petani yang selalu menggunakan jangkoi sebagai tempat memasukkan padi hasil panennya.

\section{Teori Kreasi}

Kreasi merupakan suatu tindakan dalam menciptakan sebuah karya yang berpedoman pada bentuk sebelumnya, kemudian mengolahnya menjadi bentuk baru dengan penambahan unsur-unsur yang mendukung proses penciptaan tersebut. Djelantik (2004: 67) menjelaskan bahwa: "Kreasi merupakan penambahan unsur-unsur baru kedalam sesuatu yang telah ada atau mengolahnya dengan cara baru yang belum pernah dilakukan dan bersifat asli. Karya seni yang demikian disebut dengan gubahan atau pengolahan suatu pelaksanaan berdasarkan pola pikiran baru atau disebut juga dengan seni baru yang diciptakan sendiri. Kreasi yang dimaksud bukan hanya wujud yang baru tetapi adanya sebuah pembaharuan dalam konsep-konsep estetika atau penemuan konsep baru untuk menciptakan sebuah karya seni”.

\section{METODE PENELITIAN}

\section{Observasi}

Observasi adalah salah satu metode yang digunakan dalam mengamati sesuatu untuk mendapatkan hasil yang lebih akurat. Observasi yang dilakukan merupakan langkah awal didalam pencarian ide penciptaan seperti pengambilan data-data yang berkaitan dengan kuluk, anyaman, serta benda bersejarah yang menjadi ikonik masyarakat Kerinci. Data tersebut bersumber dari buku bahkan wawancara yang dilakukan dengan narasumber. 


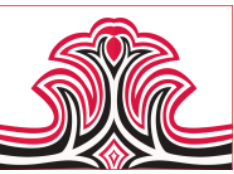

2. Wawancara

Wawancara yaitu suatu cara yang digunakan dalam sebuah penelitian untuk memperoleh informasi tentang sesuatu yang akan di gali. Selain itu, wawancara sering digunakan untuk mendapatkan informasi mengenai fenomena yang terjadi di masyarakat, yang mana fenomena tersebut tidak bisa diamati sendiri secara langsung. Sehubungan dengan paparan di atas, pengkarya melakukan wawancara didalam proses pencarian informasi, keterangan, pendapat, melalui proses tanya jawab dengan beberapa narasumber mengenai bentuk kuluk masa lampau, seperti bapak Nazaruddin yang merupakan salah satu pemegang gelar adat di Kerinci depati muda susun negeri, dalam wawancaranya beliau menjelaskan bahwa kuluk yang dipakai oleh perempuan Kerinci bukan sekedar meletakkan di atas kepala tetapi pemaknaan kuluk tersebut harus dipahami oleh perempuan-perempuan Kerinci agar dapat diterapkan dalam kehidupan seharihari (Nazaruddin, 2020).

\section{Dokumentasi}

Dokumentasi merupakan proses pengumpulan bukti dari keterangan dan penyediaan dokumen-dokumen dengan menggunakan bukti yang akurat berdasarkan pencatatan berbagai sumber informasi. Selain itu, dokumentasi dapat juga diartikan sebagai salah satu proses pengumpulan data dengan cara pengambilan gambar untuk dijadikan sebuah bukti yang akurat.

Sugiyono (2018: 329) menegaskan bahwa, dokumentasi adalah suatu cara yang digunakan untuk memperolah data dan informasi dalam bentuk buku, arsip, dokumen, tulisan, angka dan gambar yang berupa laporan serta keterangan yang dapat mendukung penelitian. Dokumentasi yang digunakan dalam proses penciptaan karya yaitu pengambilan beberapa foto yang berkaitan dengan bentuk kuluk yang dipakai oleh perempuan Kerinci dalam prosesi adat yang ada di masyarakat Kerinci, kemudian ditelaah dan dihubungkan dengan karya yang diciptakan.

\section{HASIL DAN PEMBAHASA}

1. Hasil

1). Karya I

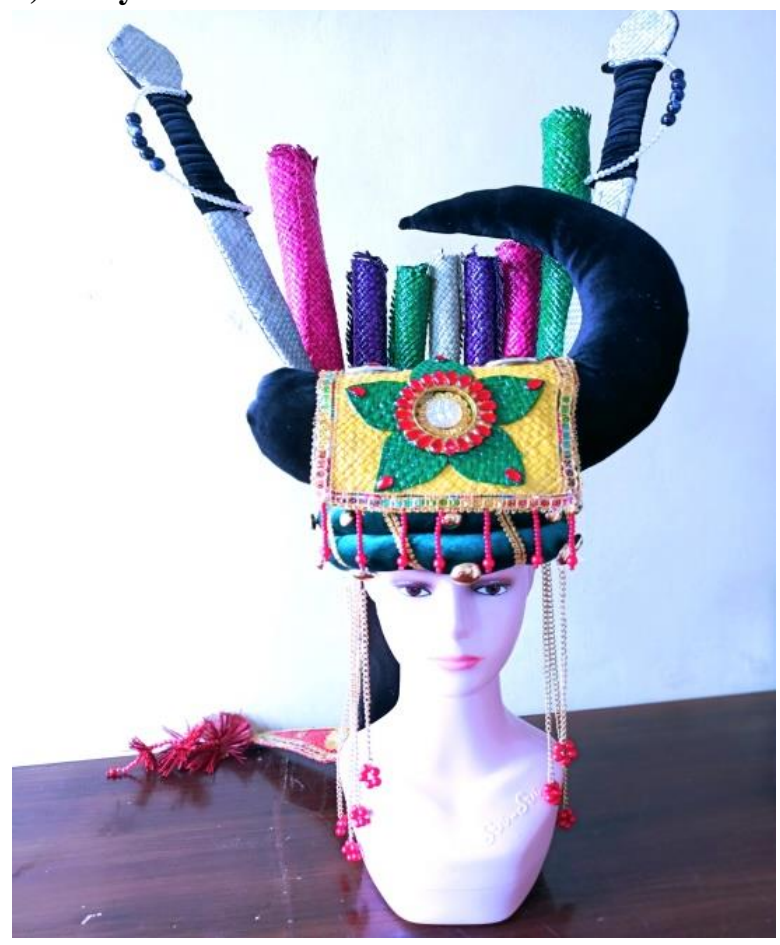

Gambar 1.

Kuluk Karamentang (Linda, 2021)

Keterangan:

Judul

Ukuran

Bahan

Teknik

Warna

Tahun
: Kuluk Karamentang

: $25 \mathrm{~cm} \times 65 \mathrm{~cm}$

: Daun pandan, kain beludru, swarovsky, rantai nori, mutiara ceko dan manik-manik. : Anyaman, jahit dan tempel.

: Hitam, hijau tua, merah, kuning, merah muda, ungu, putih dan silver. : 2021 


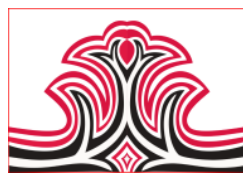

2). Karya II

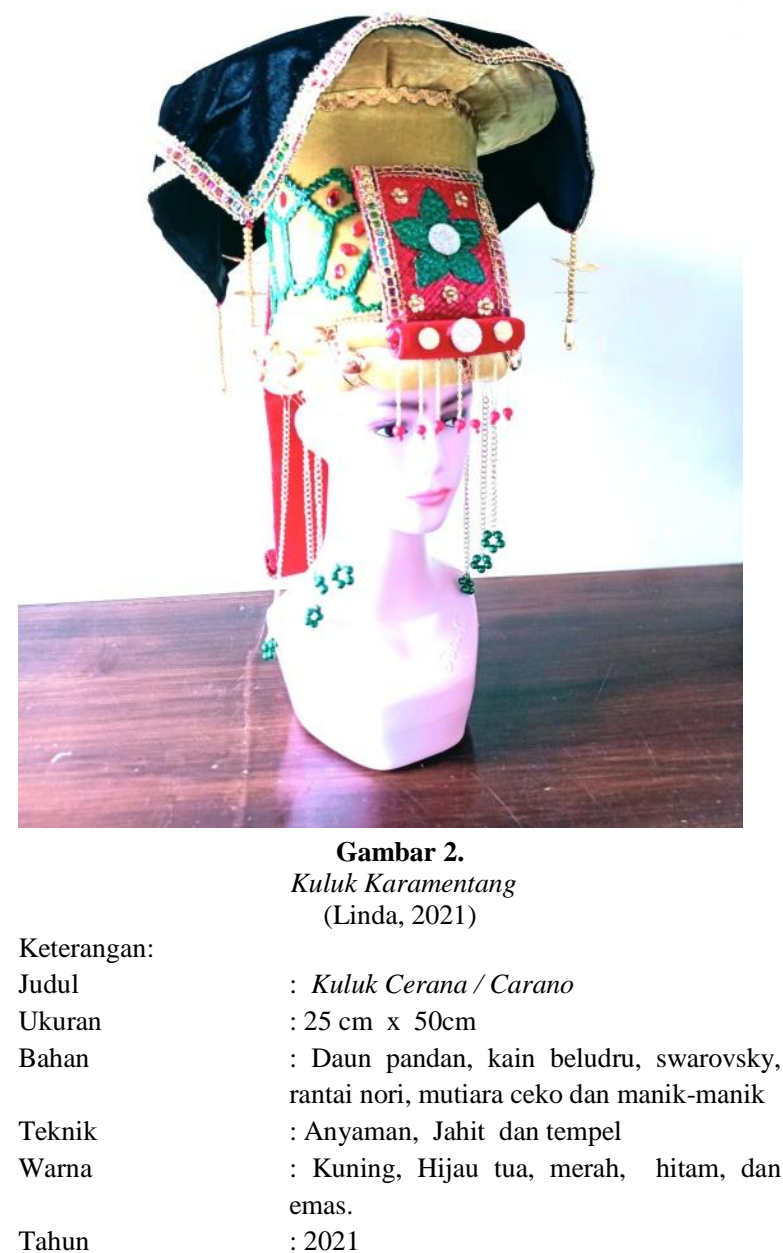

\section{Pembahasan}

\section{1). Karya Kuluk Karentang}

Karya dengan judul "Kuluk Karamentang” ini terinspirasi dari bendera adat masyarakat Kerinci yang dinamai dengan Karamentang. Karamentang merupakan bendera adat yang panjang sampai 10 meter bahkan ada yang lebih. Bendera ini berbentuk segitiga terbalik sedangkan di bagian atas karamentang dipasang lambang tanduk kerbau. Bendera ini dikibarkan di daerah yang akan menggelarkan acara adat. Pengibaran bendera ini merupakan suatu tanda bahwa di suatu daerah akan mengadakan acara adat besar-besaran. Prosesi kenduri sko masyarakat Kerinci dilengkapi dengan adanya lemang yang dimasak secara massal oleh kaum perempuan yang ada di masyarakat Kerinci. Selain itu, kehadiran hulubalang juga sangat penting didalam prosesi adat masayarakat Kerinci, sebab hulubalang mempunyai tugas sebagai penjaga keamanan selama acara berlangsung.
Gorga : Jurnal Seni Rupa

Volume 10 Nomor 02 Juli-Desember 2021 p-ISSN: 2301-5942 | e-ISSN: 2580-2380

Karya kuluk ini dibuat pada tahun 2021, menggunakan bahan kain beludru berwarna hitam dan hijau tua, batu swaroski berwarna merah, mutiara bulat warna putih dan hitam. Selain itu, kawat berwarna silver yang digunakan untuk membuat kerangka kuluk dengan ukuran $2 \mathrm{~mm}$ dan rantai nori warna kuning emas. Bentuk karya dirancang dengan dua tingkatan lingkaran dengan menggunakan bahan kain beludru berwarna hijau tua. Warna hijau pada lingkaran kuluk dimaknai sebagai suatu kedamaian dan kesejahteraan di dalam membina rumah tangga. Sedangkan penggunaan warna hitam pada tanduk kerbau merupakan sebuah simbol dari hulubalang yang memegang gliwang (pedang panjang).

Bagian belakang lingkaran kuluk terdapat gulungan anyaman pandan yang dismbolkan sebagai lemang, sedangkan bagian samping kiri dan kanan anyaman tersebut terdapat Gliwang (pedang panjang) yang merupakan simbol bahwa, adanya hulubalang yang berperan sebagai penjaga keamanan. Selanjutnya di bagian kiri dan kanan bawah lingkaran kuluk terdapat rantai nori yang berjumlah tujuh buah yang melambangkan tujuh kunci yang dipegang oleh perempuan Kerinci di dalam rumah tangga.

\section{2). Karya Kuluk Cerana}

Karya dengan judul "Kuluk Cerana/carano" ini terinspirasi dari bentuk cerana/ carano yang berfungsi sebagai tempat sirih nan sekapur dan rokok nan sebatang yang akan disuguhkan kepada tamu. cerana ini digunakan oleh masyarakat Kerinci pada saat menunggu tamu di pintu lawang (pintu gerbang). Karya kuluk ini dibuat pada tahun 2021, menggunakan bahan kain beludru berwarna kuning, batu swaroski berwarna merah, dan manik-manik berwarna emas. Selain itu, kawat berwarna silver yang digunakan untuk membuat kerangka kuluk dengan ukuran $2 \mathrm{~mm}$ dan rantai nori warna kuning emas. Bentuk karya dirancang dengan dua tingkatan lingkaran dengan menggunakan bahan kain beludru berwarna kuning. Warna kuning pada lingkaran kuluk dimaknai sebagai suatu keagungan depati ninik mamak. Sedangkan penggunaan warna hijau pada anyaman disebelah kiri dan kanan bagian kaki cerana/cerano merupakan simbol dari ketenangan hati dari depati ninik mamak dalam menyelesaikan segala permasalahan yang ada di masyarakat.

Bagian depan cerana terdapat anyaman berwarna merah dengan kombinasi motif tampuk nio (kelopak kelapa) dan motif matoahai (matahari) serta di bagian belakang cerana terdapat anyaman berwarna merah yang dilambangkan sebagai keberanian. Selanjutnya di bagian kiri dan kanan bawah lingkaran kuluk terdapat 
rantai nori yang berjumlah tujuh buah yang melambangkan tujuh kunci yang dipegang oleh perempuan Kerinci di dalam membina rumah tangga.

\section{KESIMPULAN DAN SARAN}

\section{Kesimpulan}

Penciptaan karya seni yang berjudul "Kreasi kuluk perempuan kerinci dari anyaman pandan", merupakan sebuah karya yang terinspirasi dari makna dan nilainilai yang terkandung dalam kuluk yang dipakai oleh perempuan Kerinci di masa lampau. Pemaknaan kuluk tesebut berkaitan erat dengan sifat dan tanggung jawab seorang perempuan Kerinci yang sudah menikah, dalam mengarungi dan membina sebuah rumah tangga serta kepatuhannya kepada suami dan ketaatannya kepada Allah SWT.

Kuluk merupakan ikat kepala atau penutup kepala yang digunakan oleh perempuan Kerinci sebagai mahkota kepala. Penciptaan karya seni kriya yang berjudul "Kreasi Kuluk Perempuan Kerinci dari Anyaman Pandan" bertujuan untuk memperkenalkan kembali makna filosofis yang terkandung di dalam kuluk perempuan Kerinci yaitu dengan cara diletakkan di atas kepala sebagai mahkota kepala perempuan hal ini dimaknai bahwa perempuan Kerinci yang sudah menikah memiliki tanggung jawab yang harus dijunjung tinggi. Selain itu, tujuh kunci yang melambangkan bahwa peranan perempuan Kerinci setelah menikah adalah pemegang kunci di dalam rumah tangga, yaitu kunci umouh (rumah), kunci kamar, kunci bilik (lumbung padi), kunci pura (lemari), kunci peti, kunci dapur dan kunci hati. Kuluk Perempuan Kerinci sebagai salah satu ide penciptaan karya seni dalam pengembangan bentuk sebelumnya, yang kemudian dikreasikan menjadi bentuk baru yang berkaitan dengan benda-benda ikonik di masyarakat Kerinci.

\section{Saran}

Perwujudan karya kreasi kuluk perempuan Kerinci dari anyaman pandan, yang memunculkan kembali makna dan nilai-nilai filosofi yang terkandung di dalam kuluk yang dipakai oleh perempuan Kerinci di masa lampau, dan kemudian dijadikan sebuah karya kreasi baru dengan menampilkan bentuk simbolis yang mewakili makna tersebut. Proses penciptaan karya ini membutuhkan analisa makna dan nilai-nilai filosofinya, agar pemahaman masyarakat Kerinci simpang siur. Masing-masing karya saling berhubungan antara satu dengan yang lainnya, dan berkaitan erat dengan kehidupan masyarakat Kerinci serta peranan perempuan di dalam masyarakat Kerinci.
Gorga : Jurnal Seni Rupa

Volume 10 Nomor 02 Juli-Desember 2021 p-ISSN: 2301-5942 | e-ISSN: 2580-2380

Penciptaan karya ini dapat dijadikan sebagai sumber acuan untuk pengkarya-pengkarya yang ada di Kerinci dalam pengembangan bentuk yang baru. Selain itu, pengkarya mengharapkan kepada masyarakat Kerinci agar tetap melestarikan budaya menganyam dan melahirkan karya-karya inovasi dari anyaman pandan.

\section{DAFTAR RUJUKAN}

Akmal, Ahmad. (2013). Ekspresi Bentuk Simbolik Seni Ritual MAKAN BAJAMBA. Padangpanjang: Institut Seni Indonesia Padangpanjang.

Djelantik, A.A.M. (2004). Estetika Sebuah Pengantar. Bandung: Masyarakat Seni Pertunjukan Indonesia.

Kartika. Dharsono Sony. (2017). Seni Rupa Modern. Edisi Revisi. Bandung: Rekayasa Sains.

Linda, Nofi. (2021). “Kuluk Kerinci”. Hasil Dokumentasi Pribadi: 14 Juli 2021.

Nazaruddin. (2020). "Kuluk Kerinci”. Hasil Wawancara Pribadi: 15 November 2020.

Seragih, Y. G., \& Azis, A. C. K. (2021). Tinjauan Hasil Gambar Ilustrasi Kartun dengan Objek Binatang. Ekspresi Seni: Jurnal Ilmu Pengetahuan dan Karya Seni, 23(2), 302318.

Sugiyono. (2018). Metode Penelitian Kuantitatif. Bandung: Alfabeta.

Sobur, Alek. (2003). Semiotika Komunikasi. Bandung: PT Remaja Rosdakarya. 